\title{
Granulação a seco de uma massa cerâmica para grês porcelanato
}

\section{(Dry granulation of a ceramic paste for porcelain stoneware tile)}

\author{
V. G. Sampaio, B. C. A. Pinheiro, J. N. F. Holanda \\ CCT-LAMAV, Universidade Estadual do Norte Fluminense, Av. Alberto Lamego 2000, \\ Campos dos Goytacazes, RJ 28013-602 \\ holanda@uenf.br
}

\begin{abstract}
Resumo
São apresentados os resultados de um estudo sobre a granulação a seco de uma massa cerâmica para grês porcelanato. A preparação da massa é uma das etapas mais importante na ciência de processamento cerâmico. A massa cerâmica foi formulada usando caulim, albita e quartzo em proporções pré-determinadas. As matérias-primas foram moídas a seco e em seguida microgranulada utilizando um granulador intensivo contra corrente Eirich. Foram determinadas as seguintes características da massa cerâmica granulada: composição química, distribuição de tamanho de grânulos, morfologia, massa específica aparente, massa específica vibrada, plasticidade, índice de Hausner e o comportamento de compactação. Com base nos resultados pode-se concluir que o processo via seca foi efetivo na granulação da massa cerâmica para grês porcelanato.
\end{abstract}

Palavras-chave: granulação, grês porcelanato, via seca.

\begin{abstract}
This work presents the results of a study concerning on the dry granulation of a porcelain stoneware tile paste. The paste preparation step is very important in ceramic processing science. The ceramic paste was formulated using kaolin, albite and quartz in determined proportions. The raw materials were dry-ground and then microgranulated by using a Eirich granulator of high intensity. The following parameters for the granulated ceramic paste were determined: chemical composition, granule size distribution, morphology, apparent density, tap density, plasticity, Hausner index, and compaction behavior. According with the results the dry process was effective in the granulation process of the porcelain stoneware tile paste.
\end{abstract}

Keywords: granulation, porcelain stoneware tile, dry process.

\section{INTRODUÇÃO}

O setor de revestimento cerâmico brasileiro ocupa uma posição de destaque no cenário mundial de revestimentos. Em 2004 a produção brasileira de revestimentos cerâmicos de pisos e parede foi da ordem de 566 milhões de metros quadrados, que corresponde a $8,6 \%$ da produção mundial [1]. Dentre as várias classes de revestimentos produzidos no Brasil, seguramente o grês porcelanato é a tipologia mais avançada em termos de qualidade com considerável aumento de produção. $\mathrm{O}$ grês porcelanato é um material polifásico (mistura de vidro, quartzo e mulita) definido como um revestimento cerâmico impermeável e homogêneo, esmaltado ou não, branco ou colorido artificialmente [2,3]. Além disso, apresenta excelentes características técnicas em termos de resistência mecânica, química e ao congelamento. O nível de porosidade aberta em grês porcelanato é relativamente baixo $<0,5 \%$ [4], sendo que os produtos comerciais de mais alta qualidade apresentam valores na faixa de $0,0-0,1 \%$. O processo produtivo de grês porcelanato segue tipicamente a rota da tecnologia dos pós [5]: preparação da massa cerâmica, prensagem uniaxial, secagem e sinterização em altas temperaturas $\left(1180-1240{ }^{\circ} \mathrm{C}\right)$ usando ciclos de queima rápidos, geralmente inferiores a $60 \mathrm{~min}$.

A preparação da massa cerâmica constitui-se na primeira fase no processo produtivo de revestimentos cerâmicos. Isto se deve a necessidade de que a massa preparada propicie a granulometria, morfologia e umidade adequadas para uma boa fluidez durante o preenchimento da matriz de compactação. A rigor esta etapa consiste basicamente na granulação da massa cerâmica. $O$ processo de granulação pode ser definido como a aglomeração intencional de partículas finas pela adição de água ou solução ligante, para formar aglomerados de tamanhos controlados denominados de grânulos [6]. Existem diversas formas de se realizar o processo de granulação de pós finos [6-10]. Entretanto, no 
setor de revestimentos cerâmicos esta etapaétradicionalmente feita por dois processos distintos denominados de processo via úmida e processo via seca $[5,11]$.

No presente trabalho será dada ênfase ao processo via seca. Isto se deve ao fato de que este processo tem despertado nos últimos anos grande interesse no setor de revestimentos cerâmicos. Ressalta-se, ainda, que cerca de $53 \%$ da produção brasileira de revestimentos cerâmicos é obtida através do processo via seca [12]. Tal processo pode ser usado na preparação de massas de base branca, como o grês porcelanato, e também em massas de base vermelha para monoqueima rápida de pisos [13, 14]. Além do mais, este processo é de alto interesse prático uma vez que reduz custos e minimiza impacto ambiental, quando comparado com o processo via úmida (spray dryer).

O processo via seca consiste basicamente na moagem a seco das matérias-primas, seguido pela granulação do pó fino [15, 16]. Na etapa de moagem são usados moinhos que permitam a obtenção de fina granulometria com elevada superfície específica, que favoreça a gresificação da massa durante o processo de sinterização. A granulação é realizada geralmente em granulador de forma senoidal com adição de água. As partículas umidificadas tendem a aglomerar-se em torno de um núcleo para formar grânulos maiores. A aglomeração é causada principalmente pela coesão entre as camadas de umidade que encobre as partículas. Assim, os grânulos são compostos de partículas primárias ligadas entre si por meio de forças superficiais e pontes sólidas. As forças superficiais são forças de Van der Waals ou eletrostáticas entre as partículas, ou ainda forças de capilaridade devido à presença de líquido dentro do grânulo. Além disso, a ação mecânica de turbulência no granulador aumenta os contatos entre as partículas, que influencia a taxa de formação dos grânulos. A quantidade de umidade dos grânulos apropriada para a operação de prensagem é ajustada em secador de leito fluidizado. Os pós granulados por via seca têm características tecnológicas próximas daqueles obtidos por via úmida [11]. Apesar de sua importância industrial, a etapa de preparação da massa tem sido pouco estudada no Brasil. Existe uma lacuna na literatura sobre a preparação de massas para revestimentos cerâmicos formuladas com matérias-primas nacionais, principalmente grês porcelanato.

O objetivo principal deste trabalho é a caracterização física de uma massa cerâmica para grês porcelanato, preparada pelo processo de granulação via seca. O comportamento de compactação da massa granulada foi investigado.

\section{MATERIAIS E MÉTODOS}

\section{Materiais}

Neste trabalho foi usada uma massa cerâmica para grês porcelanato formulada com $40 \%$ em peso de caulim, $47,5 \%$ em peso de feldspato sódico e $12,5 \%$ em peso de quartzo. A composição química da massa cerâmica é dada na Tabela I. Do ponto de vista mineralógico, a massa cerâmica é constituída essencialmente por caulinita, feldspato sódico, quartzo e mica moscovita como impureza principal.
Tabela I - Composição química da massa cerâmica. [Table I - Chemical composition of the ceramic paste.]

\begin{tabular}{cc}
\hline Óxidos & \% em peso \\
\hline $\mathrm{SiO}_{2}$ & 65,05 \\
$\mathrm{Al}_{2} \mathrm{O}_{3}$ & 22,50 \\
$\mathrm{Fe}_{2} \mathrm{O}_{3}$ & 0,15 \\
$\mathrm{TiO}_{2}$ & 0,01 \\
$\mathrm{CaO}$ & 0,20 \\
$\mathrm{MgO}$ & 0,07 \\
$\mathrm{~K}_{2} \mathrm{O}$ & 1,51 \\
$\mathrm{Na}_{2} \mathrm{O}$ & 4,80 \\
Perda ao fogo & 5,79 \\
\hline
\end{tabular}

\section{Metodologia}

O fluxograma do processo de granulação via seca utilizado é mostrado na Fig. 1. O processo de granulação da massa cerâmica foi realizado por três operações distintas: moagem, mistura e aglomeração. As matériasprimas devidamente secas foram moídas e misturadas durante 60 min usando um moinho de laboratório até a não retenção do pó em peneira de 325 mesh $(45 \mu \mathrm{m}$ ABNT). A distribuição de tamanho de partículas primárias da massa cerâmica foi determinada de acordo com a norma NBR 7181-84 [17]. A plasticidade da massa cerâmica foi também determinada. A massa cerâmica foi então submetida a processo de microgranulação. $\mathrm{O}$ processo consistiu na mistura, homogeneização e microgranulação da massa cerâmica, realizada num granulador intensivo contra
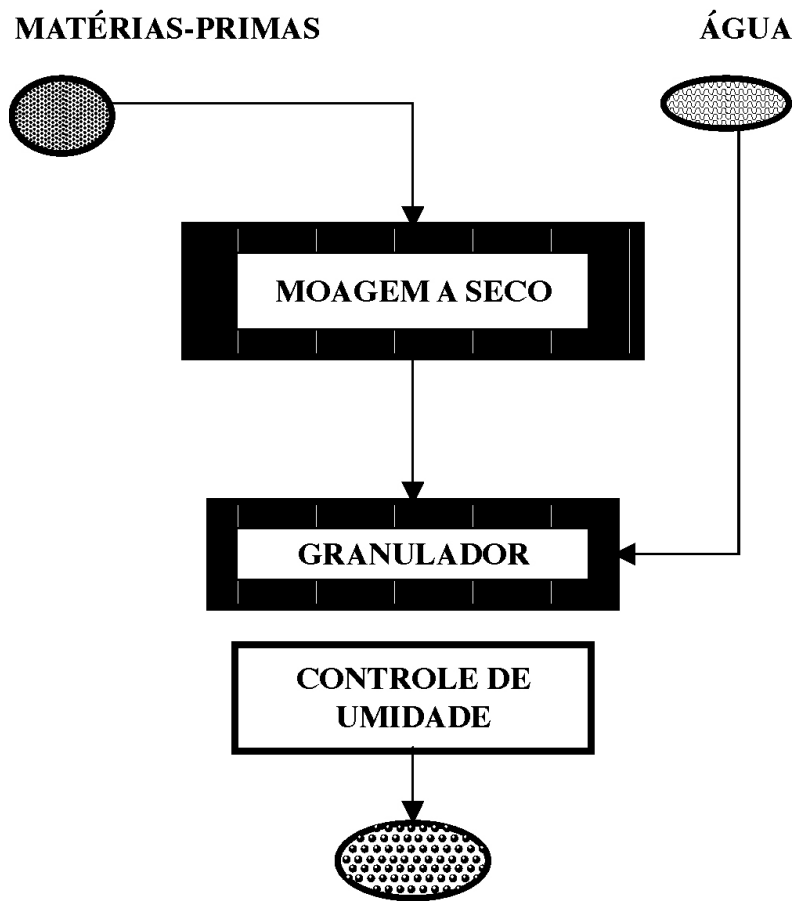

Figura 1: Fluxograma do processo de granulação via seca. [Figure 1: Outline of the dry granulation process.] 
corrente (granulador Eirich modelo R02), com umidade de granulação da ordem de 14\% (massa de umidade/massa seca) durante $5 \mathrm{~min}$. Em seguida, foi feito o controle da umidade da massa cerâmica para cerca de 7\% (base seca). Os aglomerados grossos maiores de $2 \mathrm{~mm}$ foram eliminados do processo. A massa cerâmica foi então armazenada em saco plástico e colocada em dessecador durante $24 \mathrm{~h}$ para obtenção de uma boa homogeneização da umidade.

A massa cerâmica granulada foi caracterizada em termos de distribuição de tamanho de grânulos, massa específica aparente, massa específica vibrada, índice de Hausner, plasticidade, morfologia dos grânulos e resposta de compactação. A distribuição de tamanho de grânulos foi determinada por peneiramento. A morfologia e textura dos grânulos foram observadas por microscopia eletrônica de varredura (Zeiss modelo DSM 962). O carregamento elétrico foi evitado recobrindo-se os grânulos com uma fina camada condutora de ouro. A massa específica aparente $\left(\rho_{\mathrm{a}}\right)$ da massa granulada foi determinada a partir da razão entre a massa dos grânulos $(\mathrm{g})$ e o volume aparente do pó $\left(\mathrm{cm}^{3}\right)$ de um recipiente cilíndrico de volume conhecido. A massa específica vibrada $\left(\rho_{v}\right)$ foi obtida mediante vibração da massa de pó solto em $20 \mathrm{~Hz}$ durante $10 \mathrm{~min}$, onde foi medido o volume ocupado pelos grânulos após vibração. $\mathrm{O}$ índice de Hausner foi determinado a partir da razão entre a massa específica vibrada e massa específica aparente $\left(\mathrm{IH}=\rho_{\mathrm{v}} / \rho_{\mathrm{a}}\right)$.

A massa cerâmica foi submetida a ensaio de compactação por prensagem uniaxial com ação única, utilizando uma máquina de ensaios universal (Instron modelo 5582) com taxa de carregamento de $0,5 \mathrm{~mm} / \mathrm{min}$, acoplada a um sistema de aquisição de dados experimentais. A pressão de compactação máxima aplicada foi da ordem de $60 \mathrm{MPa}$. Monitorando-se o deslocamento do pistão superior durante a compactação foi possível determinar a massa específica verde do compacto em todo intervalo de pressão aplicada. Em seguida o diagrama de resposta de compactação (densidade relativa versus pressão aplicada) foi determinado.

\section{RESULTADOS E DISCUSSÃO}

A curva de distribuição de tamanho das partículas primárias que compõem a massa cerâmicaé mostrada na Fig. 2. Nota-se que a massa cerâmica apresentou cerca de $96 \%$ de partículas com diâmetro esférico equivalente inferior a $63 \mu \mathrm{m}$. Isto indica que a massa cerâmica possui um bom nível de cominuição, sendo compatível com as massas para grês porcelanato industrial. Quanto mais fina for a granulometria da massa cerâmica, maior será a reatividade entre as partículas durante a sinterização. De fato uma boa reatividade entre as partículas irá favorecer as reações físico-químicas em alta temperatura para formação de novas fases cerâmicas e densificação do corpo cerâmico. No caso do grês porcelanato a formação de uma quantidade abundante de fase vítrea amorfa, mulita, além da dissolução parcial do quartzo [3]. Se por um lado à reatividade aumenta com a diminuição do tamanho médio das partículas, por outro pode ocorrer à diminuição da escoabilidade e da resposta de compactação da massa

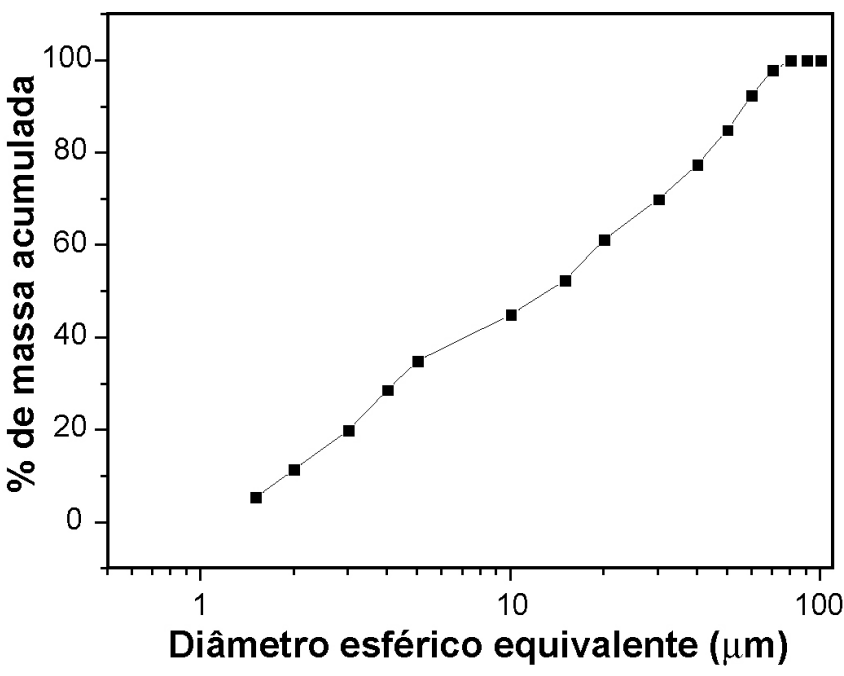

Figura 2: Distribuição de tamanho de partículas primárias da massa cerâmica.

[Figure 2: Primary particle size distribution of the ceramic paste.]

para determinadas pressões de compactação e umidade. Partículas excessivamente finas dificilmente sofrem redução significativa do seu volume durante a operação de compactação. Assim, estas partículas contribuem muito pouco para o aumento da massa específica verde dos compactos. Por isso, a massa cerâmica foi submetida a um processo de microgranulação. $\mathrm{O}$ índice de plasticidade (IP) da massa cerâmica de $14 \%$ reflete a sua mineralogia, que contém teores consideráveis de materiais não plásticos (feldspato sódico e quartzo). Os valores recomendados pela literatura [18] para piso gresificado estão compreendidos na faixa intermediária de IP $=10-20 \%$.

A Fig. 3 mostra a distribuição de tamanho de grânulos da massa cerâmica granulada através do processo via seca. Para efeito de comparação é apresentada também a distribuição de

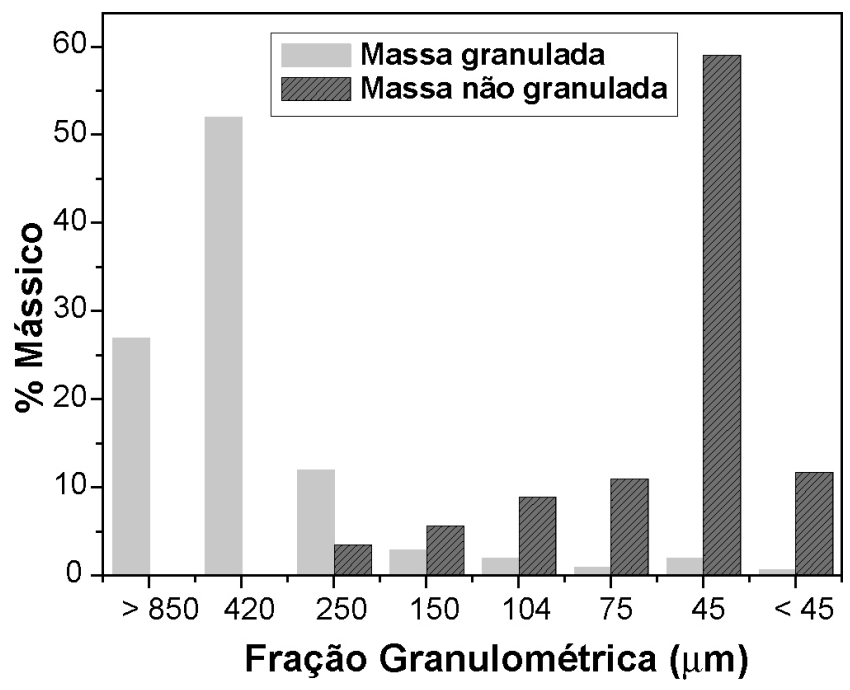

Figura 3: Distribuição de tamanho de partículas da massa cerâmica granulada.

[Figure 3: Particle size distribution of the granulated ceramic paste.] 
tamanho de grânulos para a massa cerâmica não granulada. Verifica-se que o processo de microgranulação submetido à massa cerâmica foi efetivo na formação de grânulos. A massa granulada apresenta maior percentual mássico dentro do intervalo compreendido entre $250-850 \mu \mathrm{m}$, o qual está dentro do intervalo de tamanho de grânulos para pós produzidos por via seca $[19,20]$. Observa-se também que a massa cerâmica apresentou baixa concentração de grânulos com tamanhos inferiores a $150 \mu \mathrm{m}$. Isto é importante devido este intervalo de tamanho ser caracterizado por baixa escoabilidade da massa de pó.

A morfologia e textura dos grânulos são mostrados na Fig. 4. A morfologia arredondada dos grânulos e sua superfície não excessivamente rugosa é típica de pós produzidos por aglomeração mecânica de partículas finas obtidas por moagem a seco. Estas características obtidas para os grânulos contribuirão para melhorar a escoabilidade da massa de pó. A

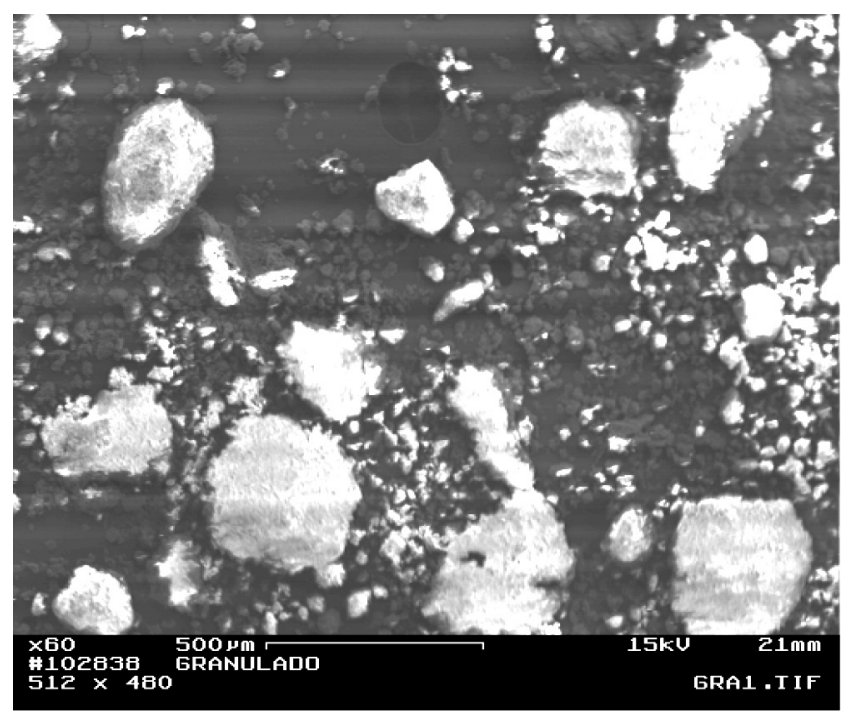

Figura 4: Morfologia dos grânulos da massa cerâmica.

[Figure 4: Granule morphology of the ceramic paste.]

Fig. 4 também corrobora a larga distribuição de tamanho de grânulos da massa cerâmica estudada.

A Tabela II apresenta importantes parâmetros tecnológicos da massa cerâmica granulada por via seca e da massa não granulada. Os resultados mostram que a massa granulada apresenta maior massa específica aparente, especificamente cerca de $25 \%$ superior. Isto se deve fundamentalmente a larga distribuição de tamanho de grânulos e a menor fricção entre os grânulos na massa granulada por via seca. A larga distribuição de tamanho de grânulos reduz a porosidade intergranular. Foi também observado que a massa específica vibrada foi cerca de $14 \%$ superior para a massa granulada. O índice de Hausner da massa granulada mais próximo da unidade $(1,03)$ comprova a sua maior escoabilidade. Isto é importante para o preenchimento uniforme da matriz, que é a etapa mais crítica da operação de compactação. Um preenchimento incorreto da matriz (falta de reprodutibilidade e uniformidade) é a causa principal da maioria dos defeitos nas peças cerâmicas.
Tabela II - Parâmetros físicos das massas cerâmicas. [Table II - Physical parameters of the ceramic pastes.]

\begin{tabular}{lcc}
\hline Parâmetros & $\begin{array}{c}\text { Massa } \\
\text { granulada }\end{array}$ & $\begin{array}{c}\text { Massa não } \\
\text { granulada }\end{array}$ \\
\hline Massa específica aparente, $\mathrm{g} / \mathrm{cm}^{3}$ & 0,68 & 0,51 \\
Massa específica vibrada, $\mathrm{g} / \mathrm{cm}^{3}$ & 0,70 & 0,61 \\
Índice de Hausner & 1,03 & 1,20 \\
\hline
\end{tabular}

A Fig. 5 mostra o comportamento da massa específica verde em função da pressão de compactação. Os resultados mostram um comportamento de compactabilidade muito similar para as massas granulada e não granulada. As curvas apresentam elevada convexidade acima de determinado valor de pressão aplicada, o qual está associado à atuação em sequiência de distintos mecanismos de compactação. Verifica-se, no entanto, que a massa granulada por via seca apresenta valores de massa específica verde superior em praticamente toda faixa de pressão de compactação aplicada. Isto demonstra que a massa granulada transmite de modo mais eficiente a carga aplicada, resultando em maior densificação do corpo cerâmico. A massa especifica verde industrial mínima para fabricação de grês porcelanato é da ordem de $1,89 \mathrm{~g} / \mathrm{cm}^{3}$ [21]. De acordo com a Fig. 5, este valor é alcançado na massa cerâmica granulada para uma pressão de compactação de cerca de $40 \mathrm{MPa}$.

Os diagramas de resposta de compactação para a massa granulada e a massa não granulada são mostrados na Fig. 6. O diagrama de resposta de compactaçãoé uma ferramenta rápida e eficiente para se inferir os mecanismos atuantes durante $o$ processo de compactação $[22,23]$. Os resultados mostram que a massa granulada apresenta maior densificação em todo intervalo de pressão aplicada, na qual alcançou densidade relativa máxima de $71,4 \%$ em $60 \mathrm{MPa}$. O comportamento de resposta de compactação das massas mostra duas regiões distintas de compactação, corroborando os resultados da

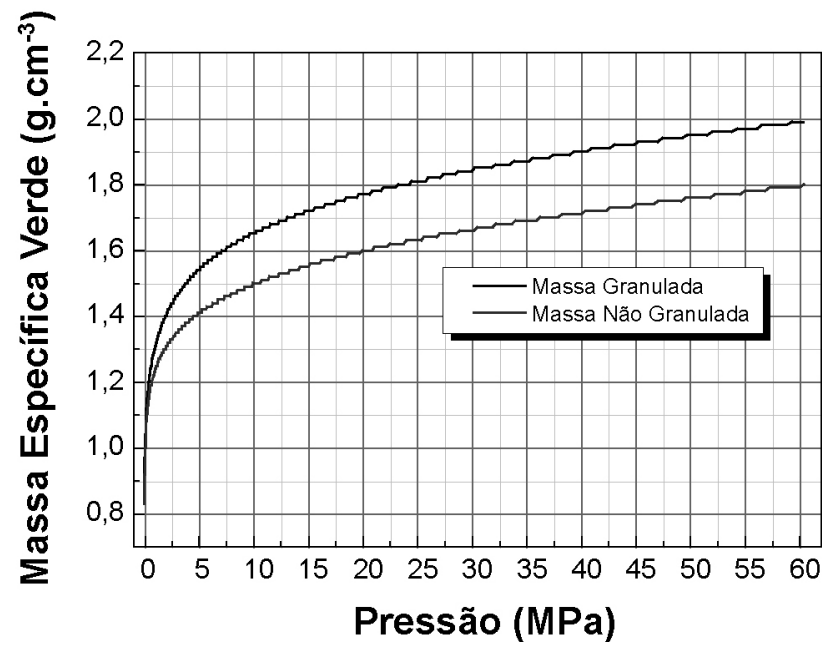

Figura 5: Massa específica verde em função da pressão de compactação.

[Figure 5: Green density as a function of the compaction pressure.] 


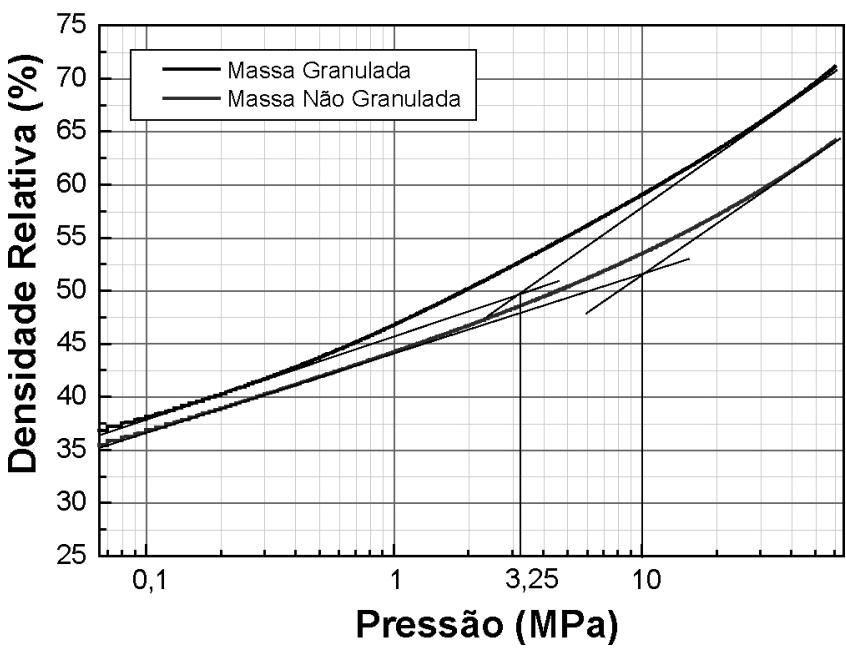

Figura 6: Diagramas de resposta de compactação para as massas cerâmicas.

[Figure 6: Compaction response diagrams for the ceramic pastes.]

Fig. 5. Essas regiões são separadas pelo valor da pressão de escoamento aparente (Pe) da massa de pó, na qual ocorreu mudança de inclinação na curva de resposta de compactação. Isto pode ser interpretado como uma indicação da mudança do mecanismo que governa o processo de compactação naquele intervalo de pressão. A massa cerâmica granulada apresentou valor de pressão de escoamento de $\mathrm{Pe}=3,25$ $\mathrm{MPa}$, enquanto que na massa não granulada foi de cerca de $\mathrm{Pe}=10 \mathrm{MPa}$. Isto comprova a maior compactabilidade da massa cerâmica granulada pelo processo via seca. Na região abaixo de Pe predomina o mecanismo de deslizamento e rearranjo dos grânulos, sem qualquer deformação e com pouco incremento na densificação. A região acima de Pe é caracterizada por grande incremento na densificação, com predomínio do mecanismo de deformação plástica dos grânulos [6]. Esta região é de grande interesse prático no processo de fabricação de grês porcelanato, na qual ocorre grande remoção da porosidade intergranular. A pressão de compactação aplicada na fabricação de grês porcelanato encontra-se geralmente no intervalo de 35-50 MPa.

\section{CONCLUSÕES}

O processo de microgranulação resultou numa distribuição de tamanho de grânulos com percentual mássico máximo na faixa de 250-850 $\mu \mathrm{m}$. A morfologia dos grânulos formados é arredondada com textura rugosa. O índice de Hausner próximo da unidade $(1,03)$ indica a boa escoabilidade da massa cerâmica. Os resultados mostram também que o processo de granulação via seca contribuiu significativamente para melhorar a compactabilidade da massa cerâmica. Isto ocorreu devido à alteração na composição granulométrica, morfologia e textura dos grânulos. Foi observado um menor valor para a pressão de escoamento aparente para a massa granulada, quando comparada à massa não granulada. $\mathrm{O}$ intervalo de pressões correspondente a segunda região de compactação $(>\mathrm{Pe})$ é o mais apropriado para fabricação de grês porcelanato. Nesta região ocorre grande redução da porosidade intergranular com grande aumento na massa específica verde.

\section{AGRADECIMENTOS}

Ao CNPq e FAPERJ pelo apoio financeiro.

\section{REFERÊNCIAS}

[1] Technical Report, World Production and Markets of Ceramic Tiles, Ind. Ceram. 26, 1 (2006) 66-67.

[2] A. P. N. Oliveira, Ceram. Ind. 3, 3 (1998) 34-41.

[3] M. Dondi, G. Ercolani, C. Melandri, C. Mingazzini, M. Marsigli, Interceram 48, 2 (1998) 75-83.

[4] ABNT, NBR 13818, Placas Cerâmicas para Revestimento: Métodos de Ensaios e Especificações (1997).

[5] A. Barba, V. Beltrán, C. Feliú, J. Garcia, F. Ginés, E. Sánchez, V. Sanz, Materias Primas Para la Fabricación de Soportes de Baldosas Cerámicas, $2^{\text {a }}$ Ed., Instituto de Tecnologia Cerámica - AICE, Castellón (2002).

[6] J. S. Reed, Principles of Ceramics Processing, $2^{\text {nd }}$ Ed., John Wiley \& Sons, New York (1995).

[7] B. J. Ennis, G.L. Tardos, A. Pfeffer, Powder Tech. 65 (1991) 257-272.

[8] P. Knight, Powder Tech. 140 (2004) 156-162.

[9] G. Bertrand, P. Roy, C. Filiatre, C. Coddet, Chem. Eng. Sci. 60 (2005) 95-102.

[10] G. Bertrand, C. Filiatre, H. Mahdjoub, A. Foissy, C. Coddet, J. Eur. Ceram. Soc. 23 (2003) 263-271.

[11]A. Vari, Raw Materials Preparation and Forming of Ceramic Tiles, Sala, Modena (2004).

[12] ABC, http://www.abceram.org.br/asp/abc_288.asp, acessado em 01/03/2007.

[13] L. J. L. Bernades, E. D. Vitti, Mundo Ceram. 10 (1994) 38-43.

[14] L. Lolli, G. Nassetti, L. F. B. Mariano, Ceram. Ind. 5 (2000) 23-27.

[15] G. Nassetti, Tile Brick Int. 6, 3 (1990) 15-18.

[16] G. Nassetti, G. Timellini, Ceram. Eng. Sci. Proc. 12, 1-2 (1991) 328-342.

[17] ABNT, NBR 7181-84, Solo: Análise Granulométrica (1984).

[18] E. Sánchez, J. Garcia, F. Ginés, F. Negre, Ceram. Ind. 1, 3 (1996) 13-22.

[19] G. Nassetti, C. Palmonari, Ceram. Ind. 2, 5-6 (1997) 11-14. [20] J. L. A. Albaro, A. B. Fuentea, J. E. E. Navarro, F. N. Medall, Bol. Soc. Esp. Ceram. Vidr. 26 (1987) 31-37.

[21] F. J. S. Arantes, D. F. Galesi, E. Quinteiro, F. G. Melchiades, A. O. Boschi, Anais do $45^{\circ}$ Cong. Bras. Cerâm., Florianópolis, SC (2001) 501603.

[22] G. L. Messing, C. J. Markhoff, L. G. McCoy, Am. Ceram. Soc. Bull. 61 (1982) 857-860.

[23] R. L. K. Matsumoto, Engineered Materials Handbook Ceramics and Glass, ASM International, USA, 4 (1991) 128-129.

(Rec. 01/03/2007, Rev. 09/05/2007, Ac. 11/05/2007) 